\title{
Uma aproximação à "língua" das cantigas galego-portuguesas
}

\author{
Xoán Carlos Lagares \\ Universidade de São Paulo
}

\begin{abstract}
Resumo:
A análise da variação e da mudança lingüística permite estudar os textos do período arcaico considerando as complexas relações que existem entre escrita e oralidade, as formas de transmissão dos diferentes gêneros textuais e as tradições discursivas em que se encaixam. A língua das cantigas, nesse sentido, apresenta características relacionadas com a tradição de cada gênero lírico, constituindo um primeiro modelo de "língua elaborada" dentro do sistema galego-português.
\end{abstract}

Palabras chave:

Lingüística histórica, língua medieval, mudança, variação.

\begin{abstract}
:
The variation analysis and language changes allow studying texts of archaic period. It is important to emphasize the complexe relations that there are between oral and written form and the different kinds of transmission, genders of texts and discursive traditions. The language of medieval songs presents characteristics of each lyrical gender and, in this sense, this language will form a first "standard language" in the Galician-Portuguese system.
\end{abstract}

Key words:

Historical Linguistics, Medieval Language, change, variation.

\section{Reflexões prévias}

\subsection{Sincronia, diacronia e mudança lingüística}

Mas o homem tem uma tal paixão pelos sistemas e pelas conclusões abstratas que não hesita em deformar deliberadamente a verdade, em deixar de ver o que está vendo e de ouvir o que está ouvindo, só para justificar a lógica.

Dostoievski, Notas do subterrâneo

A partir da publicação da obra de Saussure em 1916, a dicotomia sincronia / diacronia tornou-se uma referência fundamental para os estudos lingüísticos. Tal antinomia, na realidade, está estreitamente relacionada com a dicotomia língua / fala, pedra basilar do edifício teórico erigido pelo Curso de Lingüística Geral. O olhar 
metodológico resultante dessa visão bipolar, assim como a escolha da "língua" como matéria privilegiada da análise lingüística, parece ter criado a ilusão da existência de um objeto de estudo relativamente estático e homogêneo, reconhecível em diferentes estágios históricos rigorosamente delimitados. Nesse esquema teórico, a mudança lingüística é entendida como alteração ou perturbação ocasional do equilíbrio do sistema, como acontecimento assistemático e pontual. Segundo se afirma no Curso (Saussure 1972: 94-116), a mudança faz parte da fala, isto é, acontece nos processos de comunicação interpessoal concretos, onde realmente se manifesta na forma de inovações introduzidas pelos falantes a partir do próprio conhecimento lingüístico. Mas como o objeto da lingüística devia ser a língua, o sistema, e não a fala, o estudo da diacronia ficaria fora do escopo da ciência que estava sendo inaugurada pelo texto de Saussure.

Abrem-se assim as portas para a concretização desse objeto abstrato que chamamos língua, e para a sua identificação com a noção de "estado de língua", que corresponderia a uma sincronia determinada. A Saussure parece evidente a existência desse estado sincrônico da língua, pois propõe que o pesquisador adote a perspectiva do falante, para quem os estágios anteriores do desenvolvimento lingüístico não têm qualquer interesse, sendo que apenas um modelo de língua concreto guia a sua atividade comunicativa.

Acontece que, como indicaram vários autores, a definição e, sobretudo, a própria delimitação da língua, tal como se coloca no estruturalismo, levanta problemas de difícil solução. Segundo Coseriu (1979: 207-222), um dos questionamentos necessários diz respeito à separação radical e irreconciliável entre língua e fala, já que a língua enquanto "saber" se manifesta na fala, e dado que só esta tem existência concreta. A caracterização da língua como social e da fala como individual parece desconsiderar as múltiplas e complexas relações que se dão entre as noções de indivíduo e sociedade, que assim se apresentam, enquanto realidades essenciais, desunidas, como se fosse possível a existência de indivíduos associais e de sociedades sem indivíduos. Na realidade, o conceito de "língua" proposto por Saussure estaria calcado no de "fato social" de Durkheim. Segundo este autor, é "fato social" tudo aquilo que imposto socialmente ao indivíduo, sendo, portanto, exterior a ele. A moeda exemplificaria este conceito nas sociedades humanas. Mas, obviamente, o sistema lingüístico está longe de se poder identificar sem mais com o sistema monetário, porquanto mesmo sendo imposto ao indivíduo é por ele internalizado, e porque cada falante recria ou refaz em cada ato de fala a língua que recebe socialmente.

Saussure realiza, ainda, um raciocínio tautológico, pois, como adverte Lucchesi (2004: 52-54), ao afirmar que a língua se encontra depositada nos cérebros da massa de falantes, define estes em relação à língua, ao mesmo tempo em que delimita a língua fazendo referência ao conjunto das pessoas que a falam. Essa mesma 
circularidade argumentativa pode-se encontrar na afirmação de que determinados traços fonológicos e morfológicos constituem a fronteira que separa duas línguas porque esses traços são característicos de duas línguas distintas'.

Por esses motivos, o deslocamento do foco de atenção antes centrado na descrição das sincronias, ou dos diferentes "estados de língua", para a explicação dos processos de mudança lingüística, supôs um considerável avanço para compreender o constante dinamismo da língua. A sociolingüística variacionista (Labov 1983: 209234) oferece instrumentos para entender a mudança como um processo que acontece ligado a fenômenos de variação, de modo que as inovações que se originam e se difundem no corpo da língua podem ser estudadas em relação com determinadas variáveis lingüísticas e sociais. O registro da co-presença de formas conservadoras e inovadoras, assim como a quantificação da freqüência de uso das variantes, permite fazer uma fotografia da mudança em curso, flagrar a língua em movimento, apreender um objeto dinâmico e heterogêneo, embora com um funcionamento sempre sistêmico².

A visão da mudança lingüística que desenvolve a Sociolingüística não diferencia, obviamente, entre os dois momentos que Coseriu sinalava nesse tipo de processos, o da inovação e o da difusão, dado que a língua entendida como um procedimento social não permite reconhecer essa distinção, ao ser material e metodologicamente impossível apreender o momento em que um indivíduo introduziu por primeira vez uma inovação no uso da língua. $\mathrm{Na}$ realidade, a própria existência de variação dialetal (assim como de variação social ou de diversos registros de formalidade) seria resultado do constante e irregular processo de mudança que acontece em todas as línguas. Porém, desde os postulados da teoria gerativa, que escolhe como objeto de

1 Encontramos a mesma dificuldade para delimitar cada sincronia. É assim que as diversas tentativas de periodização da história da língua não podem evitar recorrer aos fatos políticos e sociais como marcos de referência, ao mesmo tempo em que, paradoxalmente, tentam isolar o objeto-língua de seu contexto social e histórico. Como já tentamos explicar num trabalho anterior (Lagares, no prelo), este tipo de abstração pode vir a ocultar, na realidade, a vontade de delimitação política de espaços lingüísticos nacionais. Assim acontece, do nosso ponto de vista, com a procura de traços diferenciais que possam constituir "fronteiras lingüísticas", e não apenas casos pontuais de variação diatópica, entre galego e português na Idade Média. Fazendo uso do mesmo raciocínio circular, esses traços seriam relevantes para diferenciar duas línguas pela simples razão de que são traços de duas línguas diferentes.

2 Veja-se o que diz a este respeito Maia (2002: 232): "Muito frutífera para a compreensão dos mecanismos reais de mudança linguística e para a explicação da sua origem e difusão foi o estabelecimento de relações entre a mudança e a variação linguística [...]. Ao contrário da Linguística Histórica tradicional que analisava e descrevia a mudança como um resultado susceptível de ser observado numa dada língua ou num conjunto de línguas da mesma família genética ao longo de amplos períodos de tempo, considera-se actualmente a mudança como um processo em todas as suas vertentes, desde o próprio processo de inovação linguística, para cujo esclarecimento muito contribuiu a Psicolinguística e as Ciências da Cognição, passando pelo processo social da difusão da inovação na comunidade até à completa mutação linguística e, simultaneamente, pelo processo de integração da inovação na estrutura da língua". 
estudo a Gramática ou Língua Interna dos falantes (objeto individual, mental), e não o que Chomsky (1994: 35-63) denomina Língua Externa (objeto coletivo, social), vem-se focalizando a atenção especificamente no primeiro desses momentos, o da inovação, dado que esta perspectiva teórica se desinteressa pelo funcionamento social da linguagem. Como explica Rajagopalan (2002), ao proceder a abstrair as condições concretas, centrando suas análises na capacidade de um indivíduo ideal numa comunidade homogênea para produzir sentenças gramaticais, tende a considerar as identidades lingüísticas como fixas e estáveis, embora as "gramáticas" mudem, segundo esta teoria, no momento da aquisição ${ }^{3}$. Segundo Martins (2002: 256-262), o fato de a teoria gerativa tomar como objeto a língua enquanto entidade mental e a sociolingüística centrar-se na língua enquanto entidade social faz com que ambas as perspectivas possam ser na realidade complementares:

No âmbito da lingüística histórica, o primeiro tipo de abordagem naturalmente privilegiará o estudo da mudança gramatical; o segundo tipo de abordagem privilegiará o estudo da difusão da mudança e seus percursos. Os dois olhares sobre a mudança linguística podem ser produtivamente articulados, complementando-se, pois emanam de teorias cujos objectos são distintos (2002: 259$)^{4}$.

Seja qual for a perspectiva de análise adotada, o problema que se coloca para a lingüística histórica no estudo dos processos de mudança acontecidos em momentos pretéritos, sobretudo se anteriores à existência da possibilidade técnica de registros orais, é o de como enfrentar as limitações impostas pelos poucos dados disponíveis. As informações coletadas em textos escritos de diferentes momentos históricos, que recolhem apenas, e de modo indireto, uma mínima e muito pouco representativa parte do que teriam sido as produções lingüísticas de uma época, devem ser analisadas tentando valorar a sua representatividade para a compreensão global do funcionamento da língua.

São muitas as questões levantadas pela precariedade dos dados com que somos obrigados a trabalhar, mas, de qualquer modo, parece claro que se não queremos obviar o dinamismo próprio da atividade lingüística, devemos tentar não abstrair as condições sociais da produção dos textos, e não ignorarmos as diferenças de classe, de registro, de estilo, geográficas, em virtude de uma noção de língua homogênea que, sem dúvida, nunca existiu.

3 Segundo Ligthfoot (1999: 77- 110), a origem da mudança (que acontece na competência do falante e não apenas em seu desempenho) deve ser procurada no momento da aquisição da língua pela criança, quando ela desenvolve a sua Língua Interna a partir do "input” oferecido pela comunidade lingüística de que faz parte.

4 A conciliação entre o programa variacionista e o gerativista é comum na pesquisa atual brasileira sobre mudança gramatical. Nesse sentido, pode-se ver Roberts / Kato (1993), e também Oliveira (2001). 


\subsection{A língua nos textos: escrita e oralidade}

A escrita, que parece ter de fixar a língua, é precisamente o que a altera.

Jean-Jacques Rousseau, Ensaio sobre a origem das línguas

Mikhail Bakhtin (1979: 76-95) advertia sobre a atitude da filologia tradicional a respeito dos textos antigos. Dizia o autor russo que os filólogos liam as inscrições dos tempos passados como se estas tivessem sido escritas para filólogos. É nessa interpretação monológica dos textos que ele colocava precisamente a origem da lingüística moderna, enquadrada num modelo de análise que denominava "objetivismo abstrato", pois criava o seu objeto de estudo desligando-o do mundo e das pessoas do mundo, independente das condições concretas de comunicação.

Nesse sentido, a primeira questão que devemos levantar a respeito do estudo da língua antiga é a de como interpretar os dados fornecidos por textos escritos que, enquanto enunciados que pertencem a processos comunicativos concretos, deviam ter características precisas, ao mesmo tempo em que se inseriam em tradições de escrita determinadas.

Na realidade, para considerarmos em toda a sua amplitude o problema da relação entre escrita e oralidade, devemos ter em conta que não é possível estabelecer uma distinção categórica entre essas duas instâncias, que existe um continuum que vai da oralidade, que se situa no plano da comunicação imediata, à escrita, caracterizada pelo distanciamento entre enunciação e enunciado. Oesterreicher (2001) propõe realizar ainda algumas distinções prévias. Seria preciso, segundo este autor, diferenciar entre o "meio", que pode ser fônico ou gráfico, e a "concepção", que teria a ver com as modalidades de verbalização. De tal modo que um enunciado "graficado", isto é, submetido a um processo de fixação gráfica, poderia corresponder, do ponto de vista da sua concepção, a uma modalidade de verbalização oral, como acontece no caso das transcrições dos depoimentos de testemunhas num julgamento, por exemplo. Mas fora deste exemplo extremo, colocar um enunciado por escrito supõe sempre uma re-elaboração do discurso do ponto de vista da sua concepção, existindo de fato um complexo leque de possibilidades que dependem das condições em que se produz esse tipo de interação lingüística ${ }^{5}$. Nesse sentido, resulta de grande interesse a noção de "tradição discursiva", que põe em relação as dimensões histórica, individual e universal da linguagem humana (Coseriu 1979, Schlieben-Lange 1993: 18-21). A língua escrita é elaborada de modo a produzir

5 Num artigo sobre as posições intermediárias entre fala e escrita, Barros (2001:77) conclui o seguinte: "Os usos lingüísticos que ocupariam os lugares extremos da fala e da escrita "puras" e "sem contágios" e que são definidos como termos contrários são pouco comuns e servem, antes de mais nada, como pontos de partida da caracterização que se pode fazer na diversidade de modalidades de uso que a língua apresenta". 
variedades que acabam fazendo parte de diferentes tradições discursivas, entendendo estas como os moldes histórico-normativos que se levam socialmente em consideração na produção do discurso (Jacob / Kabatek 2001: VIII) e que estão relacionados com parâmetros pragmáticos e semióticos variados. Assim mesmo, é importante salientar que estas tradições não se reduzem apenas a uma determinada comunidade lingüística.

Segundo Kloss (que citamos a partir de Jacob / Kabatek 2001), uma língua histórica começa a ser língua de cultura ao se generalizar como meio de comunicação em qualquer situação comunicativa, sendo capaz de produzir qualquer gênero textual ou tradição discursiva. $\mathrm{O}$ acesso à expressão escrita das línguas românicas durante a Idade Média obriga à elaboração de novos recursos lingüísticos para inaugurar tradições discursivas que antes pertenciam exclusivamente ao domínio do latim ${ }^{6}$. Para Jacob / Kabatek (2001: IX-XI), esse processo de elaboração constitui um importante fator de mudança lingüística, considerando que, por se tratar de língua escrita, uma atividade ao alcance só de uma pequena minoria social, essas transformações planejadas constituiriam o que, em terminologia laboviana, seria uma mudança "de cima para baixo". Restaria saber, na realidade, como essas inovações se estendem socialmente chegando a afetar a expressão oral de um número maior de falantes, e essa seria tarefa para uma sociolingüística histórica ainda muito pouco desenvolvida (Maia 1999: 24, n. 7).

Parece claro, de todos os modos, que a passagem da oralidade à escrita pode chegar a atingir o falar, mesmo porque esse processo de des-localização, des-temporalização e des-corporificação que caracteriza a expressão escrita acabam fixando o falado, oferecendo uma imagem unificada, pelo menos para uma parte dos falantes, da própria língua (Schlieben-Lange 1993: 24-30). Esse fato tem como conseqüência última a unificação das comunidades de fala. A extensão das modificações pode ser mais ou menos veloz e sempre atinge de forma irregular a massa de falantes, de modo que podemos encontrar freqüentemente traços considerados arcaicos em alguma das variedades locais da língua, isto é, podemos achar as marcas da diacronia na variação sincrônica.

Em qualquer caso, abandonando a concepção monolítica de língua, a análise textual permite estudar as mudanças diacrônicas relacionando-as também às diferentes tradições discursivas, considerando as condições de produção do discurso, os registros e as variedades envolvidas. Deste modo, podemos supor que a nossa visão da realidade lingüística num determinado momento histórico será mais ampla

6 Wright (1982) situa precisamente na reforma carolíngia da escrita latina a origem da distinção entre latim e romance. A reforma teria afetado a leitura dos textos latinos, tornando-os incompreensíveis para a maioria dos falantes. Isso obrigou a mudar a escrita dos textos de uso mais habitual que deviam ser compreendidos por todos, modificando profundamente a percepção da realidade lingüística e provocando a distinção conceptual entre o latim e as línguas românicas. 
quanto maior for o número de tradições textuais que tenhamos conseguido delimitar e analisar, de acordo com as características lingüísticas e discursivas dos testemunhos escritos disponíveis.

\title{
2. A oralidade e a diacronia nos textos medievais
}

Imprimir um texto medieval (como somos forçados - felizmente - a fazer) comporta um contra-senso histórico que as prudências editoriais não podem simplesmente corrigir.

Paul Zumthor, A Letra e a Voz

A cultura da Idade Média é uma cultura da oralidade, em que uma exígua minoria social possui o conhecimento técnico necessário para escrever e/ou decifrar os textos escritos, cujo conteúdo a maioria dos falantes pode conhecer apenas através de leituras públicas. Isto quer dizer que a oralidade medieval pode ser caraterizada, segundo Paul Żumthor (1993), como uma "oralidade segunda", onde a expressão escrita não está simplesmente ausente, diferentemente do que acontece numa "oralidade primária", sem qualquer contato com a escrita. Poder-se-ia ainda falar da existência de uma "oralidade mista" durante a Idade Média, por a influência do escrito permanecer externa, parcial e atrasada.

\begin{abstract}
Invertendo o ponto de vista, dir-se-ia que a oralidade mista procede da existência de uma cultura "escrita" (no sentido de "posuidora de uma escritura"); e a oralidade segunda, de uma cultura "letrada" (na qual toda expressão é marcada mais ou menos pela presença da escrita). Entre os séculos VI e XVI, prevaleceu uma situação de oralidade mista ou segunda conforme as épocas, as regiões, as classes sociais, quando não os indivíduos (Zumthor 1993: 18-19).
\end{abstract}

Essa característica particular da oralidade medieval faz com que Zumthor prefira usar o termo "vocalidade'. Os textos escritos na Idade Média carregam a marca da voz humana, impõem sempre uma presença, existem no imediatismo da comunicação verbal que os leitores profissionais, os recitadores e jograis estabelecem com o público.

Os textos medievais possuem, portanto, índices de oralidade, características discursivas que nos informam sobre a intervenção da voz humana ali onde a escrita funciona apenas como oralidade. A mais indiscutível prova disto continua sendo a notação musical que acompanha os poemas líricos ou épicos, onde a própria letra faz parte de uma partitura e devia ser interpretada como suporte para uma performance. Mas além deste índice fundamental existem outras características que 
fazem com que os textos medievais carreguem a marca da oralidade, motivadas pela presença do contexto situacional no momento em que se estabelece a comunicação com o público, informando-nos sobre a intervenção da voz humana, colocando o enunciado sempre num "aqui" e num "agora". Sem sairmos do âmbito da lírica, poderiam servir como exemplo um bom número de rubricas explicativas dos cancioneiros profanos galego-portugueses que, em vez de explicar o contexto que permitiria interpretar algumas cantigas escarninhas, funcionam apenas como títulos, fazendo parte do espetáculo na forma de apresentação dos poemas. Algumas delas reproduzindo, mesmo, a aequivocatio que articula o conteúdo da cantiga. Possivelmente não explicam nada porque toda explicação se tornava desnecessária na posta em cena espetacular, que contava com seus próprios recursos para contextualizar os fatos diante do auditório. Contrariamente, aquelas que realmente foram destinadas à escrita, cumprindo a função de conservar para o futuro um reflexo daquele espetáculo medieval, realizam uma narração pormenorizada dos fatos, com os quais devem estabelecer uma certa distância temporal e espacial (Lagares 2000).

Na realidade, boa parte da lírica medieval (pastorelas, alvas, possivelmente cantigas de amigo...) remete a um substrato de oralidade pura ou "primária" transformado pelos poetas da corte, que domesticam a multidão das vozes e harmonizam todas as contradições no contexto da festa palaciana. A escrita, que, dado o rigor formal das composições, está na própria elaboração das cantigas e que assegura a sua transmissão na voz de profissionais do canto, interpõe os seus filtros, constituindo um processo de "formularização" (Zumthor 1993: 109). A respeito da língua, tampouco se pode desprezar a influência do nomadismo trovadoresco na interrelação entre os dialetos locais originais, ajudando na constituição de pelo menos uma "idéia" de idioma comum.

Por outro lado, a relação entre letra e som nos textos medievais não é unívoca. No âmbito galego-português a ligação existente entre a expressão gráfica e a fonética vinha sendo interpretada erradamente por alguns dos mais importantes filólogos e lingüistas. Na variação gráfica que apresentam os textos viu-se uma tentativa de representar fielmente os sons da fala, de desenvolver uma escrita fonética. No entanto, como indica Massini-Cagliari (1998: 159-178), a escrita alfabética do Cancioneiro da Biblioteca Nacional, que lhe serve de exemplificação, está baseada no sistema latino e condicionada pela atuação de uma força reguladora que corresponde à noção de "ortografia":

No sistema alfabético-fonético, o ponto de partida para representação do signo lingüístico é o significante. No processo da escrita, através do princípio acrofônico, são representados os sons das palavras. No processo inverso, o da leitura, em um sistema alfabético-fonético, o leitor reconhece primeiramente os sons das letras, a palavra, para depois fechar o ciclo e reconhecer o significado. 


\begin{abstract}
Por outro lado, em um sistema, como a escrita do português utilizada atualmente, o significado já é considerado desde a representação da palavra. Um exemplo disso é que, nos dias de hoje, para escolhermos entre as formas "conserto" e "concerto", por exemplo, temos que considerar de antemão o significado da palavra que vamos escrever. Este fato evidencia uma das diferenças cruciais entre a escrita fonética e a ortográfica - o deslocamento da unidade básica: na escrita fonética, a unidade básica é o segmento; na escrita ortográfica, a palavra (Massini-Cagliari 1998: 168-169).
\end{abstract}

Numa escrita fonética, enfim, a cada letra corresponderia um som e haveria um som para cada letra, e nela seria impossível que fossem usadas as abreviaturas que tanto abundam nos textos medievais. $\mathrm{O}$ fato de podermos reconhecer as palavras ( $\mathrm{e}$ não os sons) permite-nos ler hoje os textos do galego-português mesmo sem termos uma idéia exata de como eram pronunciados. O que constitui uma vantagem incontestável torna-se uma desvantagem para o estudioso da língua, pois aquelas vozes estão irremediavelmente extintas e só podemos ter uma idéia aproximada da realidade fonética da língua medieval. Na realidade, a diferença básica com a escrita atual consistiria não no caráter fonético da medieval, mas no fato de não existir naquele tempo um sistema ortográfico unificado e sim um feixe de "tradições escriturais" nem sempre perfeitamente diferenciadas?.

O mecanismo de reprodução dos textos provoca ainda uma outra conseqüência que caracteriza a escrita medieval em relação à atual. Podemos reconhecer neles as marcas da diacronia. Freqüentemente percebemos que ocorrem num mesmo texto traços mais arcaicos e características inovadoras de uma linha para a outra ou, às vezes, convivendo no exíguo espaço de uma mesma linha. Percebe-se, portanto, um registro das mudanças lingüísticas que nem o próprio caráter formular dos textos pode ocultar. Essa caraterística tem a ver com o seu modo de transmissão, fundamentalmente oral, que vai produzindo modificações resultantes de uma constante tensão entre as formas inovadoras, que se impunham na atualização do texto realizada por cada intérprete, e o respeito a formas arcaicas, já não mais usadas na língua comum mas que adquiriram um valor específico naquele gênero textual concreto, podendo chegar a funcionar como marcas peculiares de identificação genérica. $\mathrm{Na}$ realidade, essa tensão entre a imitação do modelo, mediante a repetição de fórmulas características, e a inovação é própria de toda a literatura medieval. Nesse sentido, a presença de variantes lingüísticas numa determinada tradição manuscrita pode ter a ver com a influência da transmissão oral, sempre múltipla, dos textos. Além disso, não podemos desprezar a ocasional intervenção dos copistas que, como já dissemos, eram também intérpretes dos textos e que

7 Para Zumthor (1993: 96-116), ainda, os copistas medievais são intérpretes que recriam os textos, estando a atividade da escrita relacionada fundamentalmente ao desenho. A escrita nesse momento histórico não transcreve, mas simboliza, ilustra a palavra. 
podiam intervir neles manifestando alguns traços das suas variedades lingüísticas particulares ${ }^{8}$.

No galego-português, Heitor Megale (2002) identifica a presença de traços lexicais, marcas grafemáticas denunciando variação fonológica, substituições e gramaticalizações que mostrariam o convívio de formas arcaicas com outras inovadoras no texto da Demanda do Santo Graal:

Tal constatação pode-se considerar como consequiência do fato de ser ele cópia feita na primeira metade do século XV de um testemunho anterior que, ou era a própria tradução do século XIII, ou cópia muito marcada, em todo caso, pela sua influência, o que permitiu ao testemunho único conservado recolher mais profusamente as variações lingüísticas. De fato, estão presentes no códice formas já antigas para o século XV, que convivem com formas da época de sua elaboração (Megale 2002: 139).

\section{Como definir a língua dos trovadores?}

Esses multilingües estão entre os escritores mais destacados do período. Mais uma vez está em dúvida a equiparação de um único eixo lingüístico, de profundo enraizamento nativo, à autoridade poética.

George Steiner, Extraterritorial. A literatura e a revolução da linguagem

George Steiner (1990: 15-21) situa no romantismo característico do século XIX a idéia de que o escritor é uma espécie de privilegiado representante da língua materna, aquele que, encarnando o Gênio, poderia expressar a visão específica do mundo que possui o Volk ou Nação. Pois, contrariamente, antes desse momento histórico, o poeta, romancista ou dramaturgo seria um permanente "desabrigado" do ponto de vista lingüístico, alguém sempre deslocado, na fronteira, construindo a sua obra sob a pressão constante de várias línguas'. Na realidade, o bilingüismo, que se

8 Tavani (2001: 111-112) atribui a essas liberdades dos amanuenses as "misérias e desventuras" do texto medieval: "Um exemplo significativo do desprimor com que se portavam os amanuenses, mesmo os profissionais, é o da adaptação dos textos ao sistema lingüístico, diferente do original, ao qual eles pertenciam: uma adaptação evidentemente útil a uma melhor compreensão por parte dos comitentes e usuários, mas também uma alteração irreparável da estrutura primitiva, tanto mais prejudicial quando a textura de partida era de tipo poético, porque então se perdiam muitas vezes a isometria e quase sempre a arquitectura rímica".

9 E posteriormente, já no século XX, essa extraterritorialidade lingüística viria caracterizar a escrita "moderna" de autores como Oscar Wilde, Samuel Beckett, Ezra Pound, Frank Kafka ou Vladimir Nabokov, entre muitos outros. 
manifestava sobretudo numa fluência expressiva em latim ou francês, seria regra entre a elite européia até o final do século XVIII.

Obviamente, é conseqüência dessa perspectiva ideológica própria do historicismo romântico a idéia de que a "língua literária" deveria ser, afinal, identificável com o conceito de "língua nacional". Sendo assim, podemos imaginar a estranheza causada pela língua das cantigas medievais, impossível de ser enquadrada nas fronteiras políticas e territoriais conhecidas, com um número considerável e significativo de cultores que não tinham o galego-português como língua primeira ou de instalação e que apenas se serviam dela para participar do espetáculo trovadoresco.

Pensamos que desse desconcerto deriva a consideração da língua dos trovadores como uma koiné artificiosa, muito distante da língua oral. Em nosso parecer, a presença de fórmulas retóricas nas cantigas não se manifesta de igual maneira em todos os gêneros da lírica trovadoresca, e mesmo que possamos detectar elementos lingüísticos "importados" do provençal ou, sobretudo nas cantigas de amigo, formas que já no século XIII poderiam ser consideradas arcaicas, exigidas pela fidelidade aos modelos de composição (a imitatio) que caracteriza a poesia medieval, a distância com a língua falada em qualquer caso não poderia ser tão grande como para considerarmos que se trata de códigos diferentes. Dada a condição de espetáculo desta manifestação cultural, num espaço, aliás, intermédio entre o erudito e o popular, com a participação festiva de todas as camadas sociais, seria difícil imaginar que a sua língua tivesse poucos pontos de contato com aquela que era falada normalmente, o qual impediria a comunicação. A simples comparação das cantigas com outros testemunhos escritos da mesma época permite desconsiderar a hipótese de a língua das cantigas constituir uma variedade extremamente afastada e artificial, apesar de possuir características retóricas ou discursivas peculiares.

Não vamos discutir aqui os motivos que teriam feito com que toda a lírica peninsular se produzisse em galego-português, e não em qualquer outro dos romances existentes, se bem parece que não se devem negligenciar explicações que enfatizam a importância política da nobreza galega nesse momento histórico (Freixeiro 2002: 19-30), o poder da igreja católica e a relevância de Compostela como centro cultural (Tavani 1990: 30-56), ou mesmo a existência de uma arte popular, de caráter oral, que serviu de substrato para a expressão artística trovadoresca ${ }^{10}$. O galego(-português) é, simplesmente, uma das línguas românicas que desenvolvem uma tradição lírica própria, como demostra o descordo plurilíngüe do trovador provençal

\footnotetext{
${ }^{10}$ Veja-se a este respeito o que conclui Carolina Michaelis de Vasconcelos (1904: 774): “Os resultados colhidos autorizam a suppôr que a verdadeira e única razão porque a lingua gallego-portuguesa veio a ser, nos sec. XII a XV, o vehículo da poesia palaciana de toda a Hespanha, é a preexistencia d' essa arte popular, sacra e profana, que abrangia os tres elementos constitutivos da lyrica primitiva: dança, musica, poesia; ou em terminologia antiga: bailada, som, palavra".
} 
Raimbaut de Vaqueiras, onde cada estrofe está escrita numa língua diferente - provençal, italiano (com traços genoveses), francês, gascão e galego-português. Nesse sentido, a identificação que se estabeleceu entre língua e gênero parece apoiar a hipótese sobre o processo de elaboração lingüística que as variedades românicas enfrentam para acolher novas tradições discursivas, sobre as transformações a que devem ser submetidas para cumprir funções, a maioria das vezes relacionadas com a escrita, para as quais não estavam preparadas, suplantando neste domínio a língua latina. A especialização genérica das línguas viria assim tornar mais rentável o investimento necessário para que se produzisse o desenvolvimento do romance. De fato, no caso da lírica peninsular, encontramos apenas duas cantigas nos cancioneiros que foram compostas em castelhano, dos reis de Castela Alfonso X e XI, e o desenvolvimento da lírica nessa língua (que acompanha o progressivo declínio da escrita em língua galega) produz-se após uma fase de transição de hibridismo galego-castelhano.

Do ponto de vista da sua adscrição geográfica, os comentários que tem suscitado a língua das cantigas se situam num continuum que vai da consideração de seu caráter fundamentalmente galego à apreciação, no pólo contrário, de sua aparência caracteristicamente portuguesa. A questão da transmissão dos textos, o fato de a grande compilação que reuniu as composições deste período histórico ter sido realizada em território português, fez com que se venha considerando a existêricia de filtros que teriam modificado aspectos da língua original das cantigas, no sentido de lhes dar um aspecto mais meridionalizante, mais acorde com os traços lingüísticos do Sul do rio Minho. Autores como Giuseppe Tavani (2001: 112-113) privilegiaram aspectos gráficos para estabelecer diferenças entre variedades galegas e portuguesas, incidindo especialmente na representação das consoantes palatais com os grafemas $<$ ll $>$ e $<$ nn $>$ ou $<\tilde{n}>$, que seriam "grafias galegas", ou com os grafemas "portugueses" $<\mathrm{lh}>\mathrm{e}<\mathrm{nh}>$. Essa variação gráfica, que na realidade, como já dissemos, corresponde a soluções divergentes de diferentes tradições escriturais, parece-nos, porém, um indício muito fraco (praticamente irrelevante) de distinção lingüística. De todos os modos, o fato de as tradições líricas peninsulares terem o seu berço em território galego poderia ter influído no uso por parte de autores portugueses de certas formas lingüísticas que não eram características das suas próprias variedades, sem que devamos considerar por isso, necessariamente, que tenha acontecido uma intervenção sistematicamente niveladora dos amanuenses portugueses.

O certo é que as cantigas medievais inauguram uma tradição discursiva, servindose para isso de elementos das línguas vizinhas, como o provençal, de onde parte a noção do "amor cortês", do árabe e do próprio latim, além de desenvolver os recursos precisos a partir do próprio sistema lingüístico ${ }^{11}$. E que nesse processo todas as

1 Sobre a influência da cultura muçulmana medieval na língua das cantigas galego-portuguesas, fundamentalmente no léxico, pode ver-se Saprykina (2002: 393-403). 
variedades do sistema galego-português podem ser utilizadas pelos compositores, de modo que nenhuma adaptação que por ventura vieram a fazer copistas portugueses de material poético de procedência galega provocou qualquer fenômeno de perda de isometria ou de deturpação da estrutura rímica das cantigas, como, segundo Tavani (2001: 111), teria acontecido com as adaptações toscanas dos poemas da escola siciliana no século XIII.

Sem dúvida, só uma descrição detalhada da língua das cantigas, relacionando a presença das variantes com variáveis diversas, tais como o gênero da composição, o cancioneiro de que faz parte, a naturalidade do trovador e a geração poética a que pertence, permitirá tirar conclusões mais apuradas. Veja-se, a este respeito, o que afirma Francisco da Silveira Bueno:

Achamos [...] que a forma atual dos nossos Cancioneiros todos não reproduz exatamente a origem. São produtos de adaptação, alterados de século para século, introduzindo os colecionadores por meio de seus copistas muitas influências do tempo dêles numa tácita tendência de modernizar tais cantigas a fim de que os augustos leitores pudessem compreendê-las mais fàcilmente. Mesmo assim, tal galego-português ilustre representa o tipo mais arcaico de língua culta que possuímos. É incomparàvelmente mais fixa e depurada do que a língua da prosa dos primeiros documentos do século XIV ou das folhas de partilha e dos testamentos de épocas anteriores. A causa, talvez, resida na pequena extensão do vocabulário e das formas sintáticas de regência e de concordância bem como de colocação. Os assuntos da poesia medieval eram poucos e sempre os mesmos. Os poetas haviam criado um certo número de expressões poéticas, de torneios de frases, de modos de dizer com os quais expressavam tais sentimentos e idéias. Era como que uma língua adrede preparada e fixada dentro da qual todos os que quisessem poetar deviam colocar-se (Bueno 1958: 73).

Porém, Monteagudo (1999) duvida da possibilidade de se aceitar para a lírica galego-portuguesa as conclusões que estudiosos do âmbito francês-ocitânico mantêm sobre a relativa uniformidade das koiné literárias, onde a variação diatópica se apresenta nos textos de modo assistemático, sem relação com o lugar de origem do compositor. E afirma o seguinte:

Probablemente, isto no é aplicable sen máis á lírica galego-portuguesa, na que a dependencia do groso da tradición manuscrita dun único centro transmisor (a corte do conde don Pedro de Barcelos), sen dúbida sobreimpuxo unha uniformización 'meridionalizante' (isto é, portuguesizante) sobre o conxunto dos textos, que iles dá unha fasquía máis homoxénea da que estes apresentaban orixinalmente. Isto, que é evidente no aspecto puramente ortográfico, precisa dun estudio máis profundo para outros aspectos (Monteagudo 1999: 90-91). 
É precisamente em alguns desses outros aspectos lingüísticos onde pretendemos centrar-nos agora, para tentar delimitar, fundamentalmente, em que medida essa variação, não apenas diatópica, mas também diacrônica (na medida em que seja possível fazer essa distinção), mantém alguma relação mais ou menos sistemática com as variáveis que mencionamos anteriormente, no intuito de elaborar uma língua literária que, pela sua formação plural dentro do sistema lingüístico galegoportuguês, poderemos definir como "inter-dialetal".

\title{
4. A variação lingüística nas cantigas galego-portuguesas
}

\author{
Assim chegamos a uma situação em que nenhuma pessoa \\ razoável poderia manter o chamado dogma neogramático: \\ que a mudança fonológica é sempre gradual, sempre regular, \\ afetando todas as palavras ao mesmo tempo.
}

William Labov, Resolvendo a controvérsia neogramática

Como dizíamos anteriormente, a variação nos textos medievais é uma consequiência do seu peculiar modo de transmissão, de caráter fundamentalmente oral e onde cada cópia escrita constitui uma nova interpretação do material textual existente. Também nas cantigas é possível detectar essa variação lingüística, apesar do seu estilo formular (e em alguns casos, como veremos, precisamente por causa dele), de maneira que diversas variantes diatópicas e diacrônicas convivem nos textos poéticos dos cancioneiros. Daremos aqui apenas alguns exemplos, com o objetivo de mostrar algumas características lingüísticas que poderiam definir a modalidade de galego-português usada pelos trovadores.

No paradigma verbal dos verbos irregulares medievais registra-se uma peculiaridade que parece identificar formas próprias do território galego em contraste com aquelas que seriam mais comuns em território português. As formas com morfema númeropessoal /-o/ para marcar a terceira pessoa do singular dos pretéritos fortes da segunda e da terceira conjugação são, segundo Maia (1986: 745-747), muito freqüentes na Galiza a partir do século XIII, sendo que na zona ao sul do rio Minho a presença destas formas é muito escassa. De fato, de todos os documentos notariais portugueses por ela analisados, apenas em um deles, localizado na cidade fronteiriça de Valença em 1411, registra-se uma forma disso, terceira pessoa do pretérito perfeito do verbo dizer. Com efeito, esta caraterística verbal constitui a forma normal do galego contemporâneo, enquanto não há registros da sua ocorrência em nenhuma outra variedade moderna do antigo galego-português. Também na cópia galega da Crônica Troiana, pelo menos na parte que corresponde ao copista galego Fernán Martís, Lorenzo (1985: 83) identifica o uso majoritário de formas com o morfe /o/ e apenas ocasionalmente registra formas verbais de pretérito como fez ou quis. 
Para comprovarmos se é possível estabelecer esta mesma relação entre as formas utilizadas e o espaço geográfico na língua das cantigas, realizamos um levantamento sobre o corpus completo da lírica profana galego-portuguesa (Brea 1996) das formas quis (3P) quiso.

A primeira conclusão que podemos tirar desse levantamento é que, com efeito, o uso de quis, como forma de pretérito de terceira pessoa do singular, e de fez é claramente maioritário nas cantigas. De outro lado, quase o mesmo número de trovadores galegos e portugueses, seis e sete, respetivamente, apresenta ocorrência da forma quiso na sua produção poética. Esses autores são os seguintes: Fernand'Esquio, Joan Lopez de Ulhoa, Joan Servando, Nun'Eanes Cérzeo, Roi Fernandiz, Vasco Fernandez Praga de Sandin, Fernan Velho, Joan Garcia de Guilhade, Joan Soarez Somesso, Joan Soarez Coelho, Rodrigu'Eanes Redondo, Vasco Rodriguez de Calvelo e D. Dinis.

Das quatro gerações poéticas estabelecidas por Oliveira (1999), a das primeiras experiências (1170-1220), a da implantação (1220-1240), a da expansão (1240$1300)$, e a do refluxo (1300-1350), quase todos os autores em que se registra uma forma quiso pertencem à terceira geração (que, aliás, é claramente a mais numerosa de todas), a dos autores que desenvolvem a sua atividade poética durante a segunda metade do século XIII. E apenas dois trovadores, um galego e um português, Joan Soarez Somesso e Vasco Fernandez Praga de Sandim, pertencem à geração anterior. Outros três trovadores que usam esta forma verbal são de outros lugares da Península Ibérica, Men Rodrigues Tenoiro, Pedr'Amigo de Sevilha e Pero Mafaldo, e participam do espetáculo trovadoresco na corte castelhana de Afonso $\mathrm{X}^{12}$.

Dado que não é possível ter acontecido qualquer intervenção dos copistas a este respeito sem que a estrutura métrica dos versos se visse afetada, podemos concluir que essa distribuição de usos das formas quiso / quis, responde bastante fielmente ao que deveria ter sido a vontade dos trovadores no momento da composição das cantigas. Pelo menos neste aspecto, verifica-se que elementos de todo o sistema linguístico podiam fazer parte de um repertório ao alcance dos autores, independentemente de que se tratasse de formas pouco usuais na própria variedade oral do poeta. A necessidade de uma sílaba a mais ou a menos para manter a isometria dos versos poderia provocar o uso de uma forma dialetal que não correspondesse à variedade oral do trovador, remetendo para um comportamento lingüístico realmente inter-dialetal. Talvez seja essa a razão pela qual encontramos várias vezes formas de pretérito com o morfe /o/ de terceira pessoa do singular em versos do rei português D. Dinis:

12 Estabelecemos a naturalidade dos trovadores de acordo com as informações biográficas mais ou menos precisas que para cada um deles oferece Lanciani / Tavani (1993). 
Ca mha senhor quizo Deus fazer tal, quando a fez, que a fez sabedor de todo bem e de mui gram valor

B 520B / V 123

\title{
[...] ca tal a quizo Deus fazer,
} que se a nom vir, nom posso viver.

\section{B 526A / V 119}

\begin{abstract}
Nostro senhor, se averei guisado de mha senhor mui fremosa veer, que mi nunca fezo nenhum prazer e de que nunca cuid' aver bom grado, pero filhar-lh' ia por galardom de a veer, se soubesse que nom lh' era tam grave, Deus foss' em loado.
\end{abstract}

\section{B 527B / V 130}

Por outro lado, existe também variação na primeira pessoa do pretérito destes verbos, fiz fige / quis quige, onde a segunda forma é resultado da palatalização consonântica por influxo da vogal palatal final e constitui o antecedente imediato do moderno galego fixen / dixen. Segundo Ferreiro (1995: 335), estas formas palatalizadas seriam um pouco mais tardias na língua medieval. Maia (1986: 745) registra formas como figy, ffige, fige e figj apenas em documentos notariais galegos. No corpus da lírica profana encontramos, no entanto, duas ocorrências de fige, em cantigas de amor do trovador português Joam Soarez Somesso e do trovador (provavelmente) galego Nuno Fernandez Torneol, que pertencem, respetivamente, à geração da implantação (1220-1240) e da expansão (1240-1300). O número das ocorrências de quige é levemente maior. Aparece em cinco ocasiões em cantigas de Afonso X, Fernan Garcia Esgaravunha, Pero Garcia Burgalês e Roi Fernandez de Santiago. Deles, apenas o último é galego, sendo que Fernan Garcia Esgaravunha (que pertence à geração da implantação) é português e os outros são castelhanos.

Como dizíamos, neste caso não podemos falar de intervenção lingüística dos copistas do reino de Portugal, dado que encontramos formas com características consideradas "tipicamente galegas" em autores portugueses. Existem, no entanto, outros casos em que podemos aventurar a presença de uma intervenção dos amanuenses, no sentido de inserirem no texto, talvez distraidamente, traços lingüísticos da própria variedade dialetal. Assim, por exemplo, nas palavras derivadas do latim LAUDARE, onde após a queda do -d- intervocálico o ditongo /ou/ ficou numa posição 
incomum, seguido de vogal, os dois resultados medievais, depois da forma mais antiga louar, são produto da monotongação (loar) ou do desenvolvimento de uma consoante labial anti-hiática (louvar). Sendo que esta última forma é mais comum nos textos redigidos em território português (Mariño 1999: 125). Pois bem, numa cantiga do jogral Joam Zorro, de quem não se conhece com precisão a naturalidade (Oliveira 1994, 376), encontramos ambos os resultados em posição de rima:

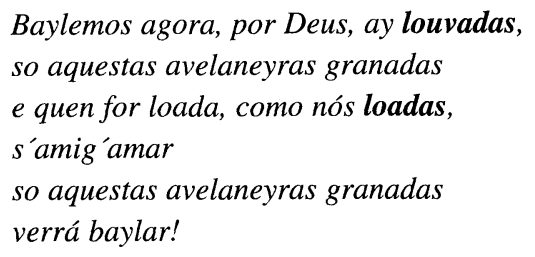

B $1158 \mathrm{~B} / \mathrm{V} 761^{13}$

Como recomendava fazer Tavani nestas ocasiões, o editor do cancioneiro de Joam Zorro, Henry Lang, corrigiu convenientemente o que parece ter sido um erro do copista. Inclusive neste caso, e considerando a presença maciça da forma loar em qualquer das suas flexões nas cantigas de amigo, não se comprova a intervenção regular do amanuense sobre os traços lingüísticos próprios da cantiga, pois apenas em uma das ocorrências do verbo aparece a variante com o desenvolvimento da consoante labial, muito provavelmente como conseqüência de um simples erro por falta de atenção no momento de realizar a cópia.

Finalmente, vários autores tinham estabelecido uma relação entre um determinado gênero da lírica, as cantigas de amigo, e algumas das características que particularizam a língua dos trovadores. Destaca-se dentre elas a forma arcaica do artigo, $l o(s)$, la $(s)$. Como se sabe, o artigo não existia em latim clássico, mas o caráter apresentador do pronome demonstrativo no latim vulgar fez com que o seu uso aumentasse progressivamente. Procedente das formas acusativas do demonstrativo latino illu, illa, illos, illas, produz como primeiro resultado lo, la, los, las, como produto de um processo de aférese por atonicidade e simplificação da geminada lateral (Ferreiro 1995: 250). Posteriormente, perde-se o [1] por fonética sintática, nas muitas ocasiões em que ficaria em posição intervocálica. No galego-português medieval, e nas falas galegas até a atualidade, aparece um alomorfe -lo, -la, -los, las, após palavras acabadas em $-r$ ou $-s$. Nos documentos analisados por Maia (1986) as formas com $l$ - após vogal registram-se apenas durante a Idade Média em

${ }^{13} \mathrm{O}$ fato de se registrar a presença da forma louvadas tanto no Cancioneiro da Biblioteca Nacional como no da Vaticana, demostra que se trata de um erro acontecido num nível anterior de transcrição das cantigas, comum a ambos os cancioneiros. 
território galego. Após palavras terminadas em $-r$ ou $-s$, é comum o uso do alomorfe também em documentos portugueses. O mesmo constata Mattos e Silva (1989: 145-148) a partir da análise dos Quatro Livros dos Diálogos de São Gregório, do século XIV.

Resolvemos testar o comportamento da forma feminina singular la após vogal no corpus completo da lírica galego-portuguesa (Brea 1996), com os seguintes resultados. A forma la ocorre após vogal em 28 cantigas. Delas, exatamente a metade, 14 cantigas, pertencem ao gênero das de amigo, cuja origem se identifica freqüentemente numa tradição autóctone ibérica, anterior à influência provençal, de modo que não é difícil conjeturar a possível identificação entre esse tipo de composição e um traço lingüístico arcaico. Em 13 cantigas, essa forma arcaica do artigo, que Leite de Vasconcelos (1966: 55) considerava pré-histórica, por não aparecer escrita em textos portugueses, figura numa expressão formular usada sobretudo em cantigas de amor, mas que também registramos noutros gêneros da lírica, "a la fe" (ou a variante, que encontramos em uma ocasião, "a la minha fe", numa cantiga de D. Dinis).

Essas duas variáveis, o gênero lírico e a expressão formular, explicam quase todas as ocorrências da forma feminina singular la após vogal. Apenas quatro casos exigem explicações adicionais. Numa cantiga de amor de Airas Nunez, trovador galego da segunda metade do século XIII, esta forma do artigo aparece na realidade numa citação do que devia ser um cantar popular de mulher:

\author{
Pois que a guirlanda fez a pastor \\ foi-se cantando, indo-ss'én manseliño; \\ e tornei-m' eu logo a meu camĩo, \\ ca de a nojar non ouve sabor; \\ e dizia este cantar ben a pastor: \\ "Pela ribeira do rio \\ cantando ía la virgo \\ d'amor;
}

quen amores á

como dormirá,

ai, bela frol?"

B 868, B 869, B $870 /$ V 454

A forma la do artigo feminino aparece também em uma cantiga de amor de Joam Airas com características semelhantes a esta, onde se relata o encontro entre o trovador e uma pastora que, como a anterior, também está cantando. De maneira, que 
em ambos os casos podemos manter a relação que tínhamos estabelecido entre esse traço lingüístico e as cantigas de amigo:

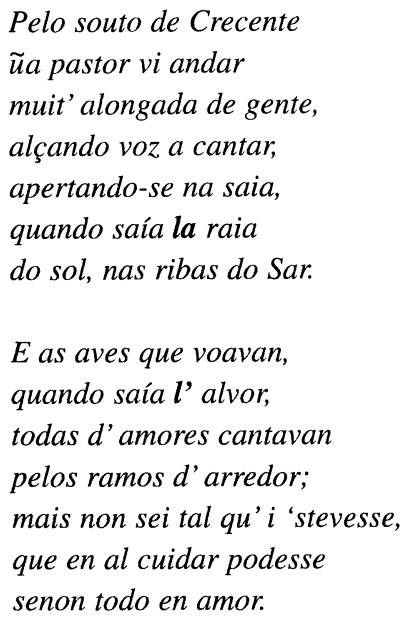

B 967 / V 554

Finalmente, apenas em duas ocorrências não é possível estabelecermos essas relações com as variáveis que mencionávamos, numa cantiga de escárnio e maldizer de Pedr'Amigo de Sevilha ("sobre la terra de Iherusalen" B 1664, V 1198) e numa cantiga de amor paralelística de Pedr'Eanes Solaz ("Vou-m' eu a la corte morar" A 284), autores ambos do século XIII.

\section{Conclusão}

Concrusám quer concrusám, / e nam há concrusám em nada.

Gil Vicente, Farsa dos Almocreves

Chegados a este ponto, temos a impressão de estar usando a palavra "conclusão" apenas em sua primeira acepção, no sentido de 'término' ou 'remate' mais que como 'inferência' ou 'resultado de um raciocínio'. Isso porque o que expressamos até aqui são apenas alguns princípios que, do nosso ponto de vista, deveriam orientar a pesquisa que tratasse de dar resposta à seguinte pergunta: que língua é a língua das cantigas?

Em vez de projetar anacronicamente sobre o passado medieval uma idéia de língua contemporânea, buscando delimitar os traços que identificariam um determinado 
estágio relativamente homogêneo e estável, deveríamos procurar na variação lingüística detectável nas cantigas as características de uma língua elaborada com elementos dialetais diversos. Essa língua dos trovadores define-se pelo lugar que a lírica medieval ocupa entre as interações comunicativas da Idade Média, sendo transmitida pela voz dos seus intérpretes numa relação peculiar entre escrita e oralidade, num espaço intermédio entre o erudito e o popular, construído a partir de tradições diversas.

$\mathrm{Na}$ realidade, enquanto resultados mais precisos de uma pesquisa abrangente sobre a língua da lírica não aparecerem, consideramos que ela é sim uma "língua elaborada", com todas as influências e dependências estilísticas de que já falamos, construída a partir das variedades existentes tanto ao norte quanto ao sul do rio Minho, com relações mais ou menos constantes entre gêneros e variantes. A sua importância na formação do galego-português radica precisamente no fato de ser a primeira tentativa, ligada ao desenvolvimento de uma tradição discursiva concreta, de estabelecer um padrão de idioma comum, embora com características e funcionalidade muito distantes das noções de territorialidade que hoje cercam a nossa idéia de língua.

\section{Referências bibliográficas}

Bakhtin, M. (1979): Marxismo e Filosofia da Linguagem (São Paulo: Hucitec).

Barros, D. Luz Pessoa de (2001): "Entre a fala e a escrita: algumas reflexões sobre as posições intermediárias”, em Dino Preti (org.), Fala e escrita em questão: 5777 (São Paulo: Humanitas-FFLCH/USP).

Brea, M. (1996): Lírica profana galego-portuguesa, 2 vols. (Santiago de Compostela: CILL Ramón Piñeiro).

Bueno, F. da Silveira (1958): A Formação Histórica da Língua Portuguesa (Rio de Janeiro: Livraria Acadêmica).

Chomsky, N. (1994): O Conhecimento da Língua. Sua Natureza, Origem e Uso (Lisboa: Caminho).

Coseriu, E. (1979): Sincronia, diacronia e história: o problema da mudança lingüística (Rio de Janeiro: Presença/EDUSP).

Ferreiro, M. (1995): Gramática histórica galega (Laiovento: Santiago de Compostela).

Freixeiro Mato, X. R. (2002): Lingua galega: normalidade e conflito (Laiovento: Santiago de Compostela).

Jacob, D. / Kabatek, J. (2001): "Introducción: Lengua, texto y cambio lingüístico en la Edad Media iberorrománica", em Daniel Jacob / Johannes Kabatek (eds.), Lengua medieval y tradiciones discursivas en la Península Ibérica. Descripción gramatical - pragmática histórica - metodología: VII-XVIII (Frankfurt am Main / Madrid: Vervuert / Iberoamericana).

Labov, W. (1983): Modelos sociolingüísticos (Madrid: Cátedra). 
Lagares, X. C. (2000): E por esto fez este cantar. Sobre as rubricas explicativas dos cancioneiros profanos galego-portugueses (Santiago de Compostela: Laiovento).

Lagares, X. C. (no prelo): "Galego-português e o mito das origens", VIII Congresso Internacional de Lusitanistas (Santiago de Compostela: Universidade de Santiago de Compostela).

Lanciani, G. / Tavani, G. (orgs.) (1993): Dicionário da Literatura Medieval Galega e Portuguesa (Lisboa: Caminho).

Lightfoot, D. (1999): The Development of Language. Acquisition, Change, and Evolution (Massachusetts / Oxford: Blackwell).

Lorenzo, R. (1985): Crónica Troiana (A Corunha: Fundación Pedro Barrié de la Maza / Real Academia Galega).

Lucchesi, D. (2004): Sistema, mudança e linguagem. Um percurso na história da lingüistica moderna (São Paulo: Parábola).

Maia, C. de Azevedo (1986): História do Galego-Português. Estado lingüístico da Galiza e do Noroeste de Portugal desde o século XIII ao século XVI (com referência à situação do galego moderno) (Coimbra: Instituto Nacional de Investigação Científica).

Maia, C. de Azevedo (1999): "Periodização na história da língua portuguesa: status quaestiones e perspectivas de investigação futura", em E, GÄRTNER / C. HUNDT / A. SCHÖNBERGER (eds.), Estudos da língua portuguesa: 21-39 (Frankfurt: Verveut).

Maia, C. de Azevedo (2002): "Dos textos escritos à história da língua", em AA.VV., História da Língua e História da Gramática (Actas do Encontro): 231-249 (Universidade do Minho / Centro de Estudos Humanísticos: Braga).

Mariño Paz, R. (1998): Historia da lingua galega (Santiago de Compostela: Sotelo Blanco).

Martins, A. M. (2002): "Mudança Sintáctica e História da Língua Portuguesa”, em Brian F. Head / José Teixeira / Aida Sampaio Lemos / Anabela Leal de Barros / António Pereira (eds.), História da Língua e História da Gramática (Actas do Encontro): 251-297 (Universidade do Minho / Centro de Estudos Humanísticos: Braga).

Massini-Cagliari, G. (1998): "Escrita do Cancioneiro da Biblioteca Nacional de Lisboa. Fonética ou ortográfica?", Filologia e Língua Portuguesa, 2: 159-178.

Mattos e Silva, R. V. de (1989): Estrutura Trecentistas. Elementos para uma gramática do Português Arcaico (Lisboa: Imprensa Nacional-Casa da Moeda).

Megale, H. (2002): “A presença dos dois períodos do português arcaico em um mesmo códice do século XV: A Demanda do Santo Graal", em Gladis Massini-Cagliari et alii. (orgs.), Descrição do Português: lingüística histórica e historiografia lingüística: 119-140 (Araquara/São Paulo: UNESP/Cultura Acadêmica Editora).

Monteagudo, H. (1999): Historia social da lingua galega (Vigo: Galaxia). 
Oesterreicher, W. (2001): “La 'recontextualización' de los géneros medievales como tarea hermenéutica", em Daniel Jacob / Johannes Kabatek (eds.), Lengua medieval y tradiciones discursivas en la Península Ibérica. Descripción gramatical - pragmática histórica - metodología: 199-231 (Frankfurt am Main / Madrid: Vervuert / Iberoamericana).

Oliveira, A. Resende de (1994): Depois do Espectáculo Trovadoresco. A estrutura dos cancioneiros peninsulares e as recolhas dos séculos XIII e XIV (Lisboa: Edições Colibri).

Oliveira, A. Resende de (1999): "Galicia trobadoresca", Anuario de Estudio Literarios Galegos 1998: 207-229 (Vigo: Galaxia / Fundación Caixa Galicia).

Oliveira, M. de (2001): "Mudança gramatical: programa de estudos”, em Rosa Virgínia Mattos e Silva (org.), Para a história do português brasileiro. Volume II: Primeiros Estudos (Tomo I): 39-55 (São Paulo: Humanitas (FFLCH-USP) I FAPESP).

Rajagopalan, K. (2002): “O conceito de identidade em lingüística: é chegada a hora para uma reconsideração radical?”, em Inês Signorini (org), Língua(gem) $e$ identidade: 21-45 (Campinas: Mercado das Letras / Fapesp).

Roberts, I. / Kato, M. (1993): Português brasileiro: uma viagem diacrônica (Campinas: Editora da Unicamp).

Saprykina, O. (2002): "A língua dos trovadores galego-portugueses no contexto da Cultura Medieval", em AA.VV, História da Língua e História da Gramática (Actas do Encontro): 393-403 (Braga: Universidade do Minho / Centro de Estudos Humanísticos).

Saussure, F. (1972): Curso de Lingüística Geral (São Paulo: Cultrix).

Shlieben-Lange, B. (1993): História do falar e história da lingüística (Campinas: Editora da Unicamp).

Steiner, G. (1990): Extraterritorial. A literatura e a revolução da linguagem (São Paulo: Companhia das Letras).

Tavani, G. (1990): A Poesia Lírica Galego-Portuguesa (Lisboa: Comunicação).

Tavani, G. (2001): "O texto medieval e as suas "misérias e desventuras"”, em Maria do Amparo Tavares Maleval (org.), Atas do III Encontro Internacional de Estudos Medievais da ABREM: 110-129 (Rio de Janeiro: Ágora da Ilha).

Vasconcelos, C. Michaëlis de (1904): Cancioneiro da Ajuda, vol. II (Lisboa: Imprensa Nacional-Casa da Moeda).

Vasconcelos, J. Leite de (1966): Lições de Filologia Portuguesa (Rio de Janeiro: Livros de Portugal).

Wright, R. (1989): Latín tardío y romance temprano en España y la Francia carolingia (Madrid: Gredos).

Zumthor, P. (1993): A letra e a voz. A “literatura” medieval (São Paulo: Companhia das Letras). 